\title{
EMANCIPAÇÃO OBJETIVADA: MARX
}

\author{
Miroslav Milovic \\ Universidade de Brasília \\ milovic@unb.br
}

\begin{abstract}
RESU M O : M arx discorre várias vezes sobre a grandeza da filosofia hegeliana, a qual, por sua vez, afirma a idéia do trabal ho. Poderíamos compreender a tarefa de $M$ arx dizendo que ele, por um lado, quer seguir essa idéia hegeliana, liberando-a, por outro, da metafísica do espírito encontrada em H egel. Trabalho sem a metafísica - essa poderia ser, em poucas palavras, a inferência que $\mathrm{M}$ arx quer extrair da filosofia de $\mathrm{H}$ egel.
\end{abstract}

Palavras-chave: Emancipação, ideologia.

Parece que Marx está seguindo o caminho da metafísica. 0 que ele procura fundamentar são os pressupostos do mundo burguês e de sua economia, os quais ficam, segundo ele, sem tematização tanto na filosofia quanto na economia modernas. Isto faz com que o mundo moderno fique baseado na ideologia. U sando a terminologia hegeliana, poderíamos dizer que, na ideologia, a verdade vale somente para 0 aspecto aparente do mundo, e não para a sua essência. N esse sentido, descobrir os pressupostos seria, então, um trabalho emancipatório, e como isto é o que Marx pretende fazer, sua filosofia é chamada de crítica da ideologia. Entretanto, aqui já aparecem várias perguntas: primeiramente, 0 que é a ideologia? 0 que ela revela? Ela faz parte do pensamento? É algo específico do capitalismo, ou algo que acompanha a filosofia durante toda a sua história? O s filósofos do passado não pensavam os pressupostos da própria filosofia; e para ilustrar isto vimos quais são as dúvidas que H egel apresentou contra Kant. Em segundo lugar, até aonde chega o projeto da crítica da ideologia? Marx o pensou até as últimas conseqüências? Por que a crítica da ideologia vai aparecer novamente na filosofia de $\mathrm{H}$ abermas? E, em terceiro, o que significa pensar os 
pressupostos? Não seria esse o caminho para as novas essências? Parece que, mesmo criticando o capitalismo, M arx ficou preso dentro do novo essencialismo.

Vamos seguir o caminho dessa crítica da ideologia em M arx. Ele acredita que a ideologia não está presente apenas no pensamento filosófico, mas se encontra em todos os aspectos do pensamento. Assim poderíamos começar com a religião, e aqui ele questiona 0 porquê de sermos religiosos. N esse ponto, ele está seguindo a crítica que Feuerbach vai articular contra a filosofia hegeliana, porém sob uma outra perspectiva. Por exemplo, a alienação não é a do espírito na natureza e na história, mas é a alienação do próprio ser humano na religião. A essência de $D$ eus é alienada do homem, e a religião é somente 0 aspecto da relação do homem consigo mesmo. ${ }^{1}$ Marx considera que isso seja verdade, e embora Feuerbach nos ofereça uma alternativa materialista, ele ainda permanece dentro da contemplação, o que faz de sua postura um materialismo contemplativo. Todavia, Marx não quer só isso, pois seu projeto, conforme nos diz a última tese sobre Feuerbach, não é interpretar e contemplar o mundo, mas transformá-lo. Portanto, a pergunta de Feuerbach continua sem resposta: por que somos religiosos? A religião relaciona-se com a alienação do ser humano, e Marx vai procurar essa alienação dentro do concreto, dentro da situação econômica, ou, como ele dirá, dentro da alienação econômica. Entre a religião e a economia, Marx irá pensar também as perspectivas da alienação filosófica e política, e aqui a referência vai ser mais uma vez a filosofia hegeliana.

0 que aconteceu com a política dentro da Modernidade? Parece que ela, desde o começo, carrega o aspecto ideológico. A final, será que a política não se questiona acerca de seus pressupostos éticos, como disseram Maquiavel e Hobbes? O ra, ela não precisa se perguntar sobre isso. Então, poderíamos dizer que essa falta de normatividade dentro da política moderna éjá o signo da ideologia, e veremos se isso é o que $\mathrm{M}$ arx quer dizer. Entretanto, a ideologia moderna relaciona-se com a falta de ética na política, ou a ideologia 
política é algo mais? A discussão sobre a relação entre política e ética retorna com os argumentos de Rousseau e Kant, ${ }^{2}$ e é Kant mesmo quem irá dar um passo importante nesse debate, voltandose para os argumentos filosóficos e mostrando que a filosofia está determinando as condições da discussão sobre o prático. Este é um motivo relevante para nossa discussão aqui, porque nos ajuda a colocar também questões sobre filosofia ao discutir política. $\mathrm{O}$ u, em outras palavras, discutindo a ideologia política podemos igualmente reconstruir a ideologia filosófica, precisamente o que M arx deseja fazer em seu primeiro encontro com $\mathrm{H}$ egel, no livro A crítica da Filosofia do Direito de H egel.

H egel, como já vimos, não ficou contente com os resultados da filosofia kantiana, e por essa razão seu projeto não é só superar os limites que Kant colocou para nossa razão, mas também como procurar a razão no âmbito do social. Então, a Filosofia do Direito termina com a discussão sobre a racionalidade, não só de nossa interioridade moral, mas também do Estado moderno; vimos daí que a Revolução Francesa foi um argumento decisivo para que se pensasse dessa maneira. Não obstante, $M$ arx se pergunta 0 que aconteceu com a Revolução Francesa, ${ }^{3}$ já que ela ainda não revolucionou a fonte de todas as alienações e nem a economia, mas somente pensou a emancipação política. Para Marx, o limite da emancipação burguesa é a política, e no entanto a emancipação burguesa não pode superar isso. Lukács irá nos dizer que o limite da consciência capitalista é o próprio capital, e, portanto, precisamos de uma nova revolução. Sendo assim, a Revolução Francesa não é a última revolução, tampouco a última resposta para a pergunta sobre a emancipação.

Aqui temos dois momentos importantes: o primeiro éa guinada para a economia; o segundo é a perspectiva de $M$ arx a respeito da filosofia que emerge dessa discussão sobre a política. É fundamental compreender que $\mathrm{M}$ arx está seguindo a filosofia do idealismo. Nos M anuscritos econômico-filosóficos, ele vai falar sobre a grandeza da filosofia hegeliana, que foi capaz de entender a essência do trabalho. 
A grandeza da Fenomenologia hegeliana e de seu resultado final - a dialética da negatividade na qualidade de princípio motor e gerador - consiste, de uma parte, em que H egel compreenda a autogeração do homem como processo, a objetivação como desobjetivação, alienação e superação dessa alienação; em que compreenda então a essência do trabalho e conceba o homem objetivado, verdadeiro, pois esse é o homem efetivo como 0 resultado do seu próprio trabalho. ${ }^{4}$

$\mathrm{Na}$ primeira tese sobre Feuerbach, Marx irá dizer que 0 idealismo alemão entendeu melhor a estrutura do mundo do que o materialismo.

A falha capital de todo materialismo até agora (incluso o de Feuerbach) é captar o objeto, a efetividade, a sensibilidade apenas sob a forma de objeto ou de intuição, e não como atividade humana sensível, práxis, só de um ponto de vista subjetivo. Daí, em oposição ao materialismo, o lado ativo tem de ser desenvolvido, de um modo abstrato, pelo idealismo, que naturalmente não conhece a atividade efetiva e sensível como tal. ${ }^{5}$

Marx assim aprendeu mais acerca do idealismo do que do materialismo, mas por quê? Porque o idealismo fala sobre a idéia do sujeito constitutivo, sobre as condições da constituição do mundo, e isso é o que $M$ arx pretende mostrar. 0 mundo é constituído, não é dado, e pensar o mundo como dado e não ver - ou não querer ver - as condições de sua constituição são exatamente os signos da ideologia. Portanto, o argumento decisivo para Marx vem da filosofia, do idealismo alemão: esta é a pergunta sobre as condições da constituição. Engels, por exemplo, ao falar da situação na Inglaterra, vai dizer que a falha principal dos socialistas ingleses é o desconhecimento do idealismo alemão. Somente mais tarde M arx torna-se um materialista que, ao criticar o idealismo, vai dizer que "o humanismo real não encontra na Alemanha inimigo mais perigoso do que o espiritualismo ou idealismo especulativo que, no lugar do homem individual real, coloca a 'Consciência de si' ou 0 
'Espírito'". ${ }^{6}$ Porém, Marx é um materialista que busca resolver a pergunta sobre a constituição do mundo dentro da economia, chegando assim até a classe operária. M elhor dizendo, seguindo 0 idealismo alemão, Marx pensa a classe operária como o sujeito constitutivo quejá apareceu na filosofia kantiana. Desse modo, creio que a gran deza de $M$ arx está precisamente em sua filosofia, e desligálo dela, voltando-se apenas para o materialismo - justamente o que aconteceu na U nião Soviética -, é tão-somente um convite para o estalinismo. Podemos dizer de certa forma que o estalinismo surgiu quando $\mathrm{M}$ arx foi desligado dos pressupostos da constituição e da parte crítica, sendo deixado com o positivismo, ou com o materialismo de uma política totalitária. É sempre bom lembrar disso para saber se 0 velho $M$ arx voltou-se, no último momento, para a economia e para a ciência, abandonando a filosofia da juventude.

Mas o que é economia? E por que razão ela significa tanto para Marx? Para responder a essa pergunta temos de atestar novamente a presença do idealismo al emão em seus argumentos. 0 ser humano não é só um ser natural, ele é o ser natural humano, é algo mais que a mera natureza: ele é o ser genérico. Sua natureza é estabelecida, pois ele cria as condições de sua própria existência. 0 único problema é que essa criação ainda não se realizou; pelo contrário, o trabalho do ser humano foi até agora a condição da alienação e não a da criação e da afirmação. A respeito da alienação, cabe dizer que a reconstrução dessa pergunta em Marx e Engels é histórica. As formas modernas da produção, da manufatura, por exemplo, já mudam a perspectiva da história; isso porque a estrutura da manufatura mostra, por um lado, as condições da produção social e, por outro, as condições da apropriação privada, o que significa que a alienação está dentro do próprio trabalho, gerando a impossibilidade de o ser humano realizar sua criatividade. Por conseguinte, superar as condições da propriedade privada significa, para M arx, a possibilidade de afirmar as novas formas do social e, nesse sentido, a revolução aparece como a superação da propriedade 
privada e das formas burguesas da economia. Aqui, Marx e Engels vêem a característica universal da classe operária, que é uma classe histórica, particular, mas que podeliberar o ser humano da alienação eque, por isso, aparece como (o) sujeito universal. Ela é, para Lukács, o novo sujeito-objeto na história: ao mudar as próprias condições, ela muda o rumo do mundo e da história.

Surge agora um ponto essencial para a nossa discussão neste contexto: ao falar sobre a estrutura da economia, Marx vai fazer uma distinção importante entre as forças produtivas e as relações de produção, qual seja, enquanto aquelas representam a relação entre 0 ser humano e a natureza, estas representam tão-somente as relações entre os homens. 0 capitalismo, por sua vez, significa a mudança na esfera da relação entre o ser humano e a natureza, relação esta que não é concreta como no passado, mas que é cada vez mais mediada pelas condições da técnica e tecnologia modernas, sendo a revolução industrial o signo dessa mudança e dessa nova mediação. Com isso, cada vez mais a ciência emerge entre o ser humano e a natureza, transformando-se numa força produtiva. Porém, a relação entre o ser humano e a natureza, a relação entre sujeito eobjeto é mediada pelas condições das relações de produção, quer dizer, pela relação sujeito-sujeito, e este é um aspecto novo da nossa discussão. Ao que parece, $\mathrm{M}$ arx elaborou aqui um novo paradigma na filosofia, pensou um novo modelo, em lugar de ficar restrito à relação sujeito-objeto, a qual, em última instância, não foi superada pelo idealismo alemão. Ele pensa a relação sujeitosujeito na forma da relação de produção, todavia esta se tornou ideológica. 0 capitalismo não pensa as condições da própria constituição, tampouco tenta mudá-las, fazendo com que a relação entre os sujeitos sociais fique reificada; por esse motivo, Marx acredita que a rel ação entre os seres humanos se transforma, então, numa relação entre coisas. Ainda hoje podemos ouvir os defensores do capitalismo dizerem que ele é a última forma da história, que com ele a história parou, que após o capitalismo não vai haver nada de novo na história e que, portanto, todos os países têm apenas de 
repetir essa experiência histórica. 0 capitalismo é, conseqüentemente, a nova forma da metafísica da presença; a metafísica surge agora com a cara do social, e essa nova metafísica chama-se economia. Nós votamos para que os políticos mudem algo, mas eles simplesmente declaram que a economia capitalista não pode ser mudada. Assim, a metafísica objetiva do passado passou pelas condições da metafísica moderna da subjetividade e terminou com as formas seculares dessa metafísica, ou com a economia. C riticar a economia poderia ser, então, o projeto da destruição da metafísica atual e constatamos assim que o projeto heideggeriano ainda não perdeu sua importância.

A economia é, por conseguinte, a nova forma de reificação na história; aparece como social, surgida posteriormenteà reificação epistemológica que, na M odernidade, começou com D escartes. A grandeza de Marx é exatamente a diagnose dessa reificação. Essa diagnose, que $M$ arx vai apresentar em 0 Capital, não é apenas uma teoria econômica, mas a filosofia relativa às condições de constituição da sociedade civil. Para revolucionar o mundo, temos de entender não só a constituição da sociedade, mas também as condições de sua constituição. Contudo, o que se encontra além da sociedade não se refere mais ao sujeito metafísico, mas ao sujeito histórico concreto, e é aqui que, como vimos, M arx fala acerca do proletariado. Temos assim os elementos necessários para diferenciar Hegel e Marx:

HEGEL

História

Senhor-Escravo

Natureza
MARX

Emancipação

SociedadeCivil

N atureza

Vimos como Hegel transformou a pergunta kantiana sobre a relação entre natureza e liberdade e entre liberdade e história. Vimos também que a pergunta sobre a história tem como pressu- 
posto a discussão sobre a relação entre senhores e escravos; só no último momento essa assimetria é superada dentro da possibilidade do reconhecimento que a R evolução Francesa oferece. Percebemos que, pensando os limites da emancipação política, Marx retorna aos pressupostos econômicos da sociedade civil, os quais devem necessariamente ser mudados a fim de realizar a emancipação. Contudo, nossa questão aqui é saber se é possível problematizar ainda mais os pressupostos da M odernidade e também apontar os limites do pensamento marxista. Ao pensar uma crítica da crítica marxista da ideologia, ou seja, uma metacrítica do pensamento de Marx, Dietrich Böhler ${ }^{7}$ articula um argumento no qual Marx não chega até os fundamentos da teoria e da prática, mas fica somente com uma teoria baseada no materialismo. Já mencionei as dúvidas contra 0 argumento que reduz $\mathrm{M}$ arx ao materialismo, mas ainda tentarei extrair dele outros possíveis questionamentos sobre $\mathrm{M}$ arx. Böhler defende que, ao não superar o contexto materialista, Marx volta ao nível anterior do idealismo alemão. Vimos que M arx está criticando a concepção espiritual da teoria hegeliana da história, uma vez que nessa concepção da história e da crítica desaparece 0 verdadeiro sujeito. Para H egel, o sujeito é sempre o espírito, e o sujeito verdadeiro, o ser humano, é somente o predicado; já, para M arx, o desenvolvimento histórico está sempre ao lado do predicado, ${ }^{8}$ o que leva Böhler a pensar que temos apenas o mundo real como 0 aspecto central da reconstrução da história e não a mediação entre os dois. ${ }^{9}$ Assim, M arx está objetivando a crítica da ideologia, ou, de outro modo, o processo da emancipação só é pensado como processo objetivo; ${ }^{10}$ um exemplo é o de que $\mathrm{M}$ arx acreditava que a superação da propriedade privada iria conduzir à emancipação, embora isso não tenha ocorrido no comunismo. Pelo contrário, fomos testemunhas das novas formas da ideologia e do totalitarismo, porque o desenvolvimento das bases produtivas não é um caminho seguro para pensar as condições da emancipação, que não é objetiva. A crítica de Böhler, ou a metacrítica da crítica da ideologia, seria o caminho para uma crítica ainda ligada à reflexão, e 
não só às condições de produção. É preciso, portanto, renovar a experiência da reflexão, mas se questiona como pensar as condições da crítica. De que tipo de reflexão precisamos? Adorno irá pensar as novas formas críticas do pensamento que afirmam o não-idêntico; $\mathrm{H}$ abermas, por sua vez, irá se concentrar nos pressupostos discursivos da constituição do teórico e do prático. E é sobre tudo isso que ainda temos de falar.

N este contexto, poderíamos entender a teoria social, ou os pressupostos filosóficos da teoria social, como o esclarecimento do processo de emancipação. Vimos que em Hegel dá-se um passo importante, pois ele conduz o sujeito moderno até o mundo histórico, e o contexto da constituição da história já é um contexto interativo, intersubjetivo. Para H egel, esse passo relaciona-se com a justificação dos pressupostos da história. No entanto, H egel parece não ter realizado o próprio projeto, porque, por um lado, ele permaneceu preso à relação entre sujeito eobjeto, não superando o modelo tradicional, e, por outro, não justificou os pressupostos dessa relação. Mesmo conduzindo o sujeito monológico kantiano às estruturas históricas da interação, a filosofia de $\mathrm{H}$ egel estabelece novamente um específico monólogo do sujeito, embora ele agora se chame 0 monólogo do espírito. Dessa forma, a fenomenologia do espírito termina como uma nova forma da lembrança platônica: agora é a lembrança do espírito sobre o trabalho terminado na história.

$M$ arx vai renovar a pergunta sobre os pressupostos históricos da constituição do espírito, da religião e da filosofia, e, como resultado, irá encontrar um fetichismo específico desse processo. 0 que é feito rel ega as condições da constituição e apresenta-se como al go natural. Problematizar o fetichismo, a ideologia da consciência moderna, é, pois, a fonte do pensamento marxista. A história não pode ser reduzida à metafísica, e aqui está, para $M$ arx, o passo entre o idealismo alemão e a crítica da ideologia. Eu acredito que, neste contexto, poderíamos reforçar a dinâmica do pensamento marxista, pois nos ajudaria a discutir se as críticas sobre o pensamento de $\mathrm{M}$ arx prepararam 0 estalinismo. ${ }^{11} \mathrm{U}$ ma certa estática e 0 essencia- 
lismo, com os quais M arx determina o caráter do social, são, para C astoriadis, os pressupostos para a burocratização da vida, ocorrida na U nião Soviética. Eu penso que a deformação do social no comunismo não está partindo da estática do pensamento marxista, mas da ruptura com a filosofia, que resultou no comunismo. Em lugar de tematizar a prática do ser humano como a fonte quase ontológica das novas formas da vida, o comunismo afirmou somente o que Marx chamava de o trabalho, quer dizer, a ação dentro do sistema existente. ${ }^{12} 0$ bviamente, a questão é muito mais complexa do que tentei apresentá-la aqui. A discussão sobre a dinâmica ou a estática no pensamento marxista teria de repensar também a perspectiva política do desenvolvimento histórico do movimento operário, e a questão da organização da classe operária, que determina a constituição da Internacional, também teria de ser discutida. É possível, portanto, falar sobre a estática do pensamento marxista dentro, por exemplo, da questão sobre a organização do movimento operário. Eu diria assim: como pensar o confronto infelizentre M arx e Bakunin? A narquismo ou movimento operário organizado? Parece que, ao se separar do anarquismo, Marx perdeu - e muito - o dinamismo da ação. ${ }^{13}$

Marx procura romper com a metafísica do passado esclarecendo as condições da constituição do nosso pensamento eda nossa vida social. "A destruição da metafísica econômica" poderia ser, então, o título do projeto marxista. Masa dúvida é se M arx executou o próprio projeto, se ele superou a metafísica. Em lugar da economia capitalista, Marx pensa uma outra economia, a socialista; muito embora, ao criticar a metafísica da economia, ele não esteja saindo do mesmo modelo da economia, o que faz com que el e guarde uma certa metafísica dentro da própria posição. Essa metafísica se reconhece como a afirmação dos processos objetivos, da emancipação objetivada.

De que espécie de pensamento precisamos hoje? A que devemos ainda relacionar o pensamento crítico? Ao marxismo? Ao comunismo? À esquerda? É possível que tenhamos de fortalecer as 
condições da reflexão contra o recado da última tese sobre Feuerbach. Para Böhler, M arx ainda não chega aos pressupostos do pensamento reflexivo, que questiona as condições da própria possibilidade e validez. ${ }^{14} \mathrm{M}$ arx não fazisso; pel o contrário, ele reduz a história à produção, ou melhor, ele reduz o caráter histórico da produção ao nível objetivo. ${ }^{15}$ De uma perspectiva intersubjetiva, temos, em H egel, uma volta para uma perspectiva quase científica, a saber, a da relação sujeito-objeto, que, segundo Böhler, está presente em M arx. No último momento, o segundo M arx, conforme apontam vários críticos, é o pensador da ciência, da economia e não mais da filosofia, o que pode ser verificado em 0 Capital, em que $\mathrm{M}$ arx pretende oferecer uma reconstrução científica. A crítica da ideologia termina, assim, numa específica redução materialista, ${ }^{16}$ ao invés de repensar as condições da teoria e da prática. M arx, ao queparece, não está fazen do isso, o que resulta na redução da história à produção. Pensando a história, $\mathrm{H}$ egel permaneceu dentro do paradigma do pensamento, enquanto $M$ arx, pensando 0 capitalismo, ficou dentro do paradigma do trabalho. Essa é a razão pela qual M arx não pode criticar H egel de uma maneira radical; ele não pode criticar a falta de reflexão em H egel porque está dividindo essa falta com ele. Logo, a crítica marxista da modernidade não chega a seu termo, ficando no meio do caminho.

Podemos colocar mais al gumas dúvidas que já mencionamos implicitamente: até aonde, por exemplo, chega a crítica marxista? Superar a alienação significa, para M arx, superar a separação entre o particular e o geral, devolver ao homem a essência alienada. M as M arx ainda trabalha com uma perspectiva essencialista? Para ele, este é o contexto para pensar a emancipação, já que ela fica ligada às essências. Entretanto, poderíamos afirmar o contrário. A questão é mostrar a emancipação além do essencial, mostrar a emancipação também do essencial.

Assim, as dúvidas sobre a objetivação da emancipação e a sobre o essencialismo em Marx levam a questionar se é possível discutir ainda os pressupostos do social e procurar as novas formas 
para pensá-lo, ou seja, as novas formas da reflexão. Com isso, parece que a mudança do capitalismo tem como pressuposto a mudança de paradigmas, ou pode ser até mesmo o fim de todos eles. Esta é a alternativa que vai acompanhar a nossa pesquisa.

A questão, também, é se podemos pensar as mudanças do social quando, ao que parece, falta o mesmo sujeito que $M$ arx tinha como referência, quer dizer, quando falta a classe operária. Esta é já a dúvida para as discussões marxistas na Rússia, a saber, como pensar a revolução sem seu sujeito que ainda falta. Este é o ponto onde se separam Plehanov e Lênin, assim como esta é a dúvida posterior dentro da Escola de Frankfurt, isto é, como pensar a teoria social sem o sujeito dessa teoria. 0 capitalismo assimila as alternativas e, dessa forma, a classe operária também éassimilada. C omo pensar, então, as mudanças sociais com uma classe já conser vadora?

Como exemplo, temosa proposta de Böhler, que diz respeito à questão da linguagem. M arx, ao criticar o idealismo, determina a dependência das superestruturas espirituais da base social. Assim, segundo Böhler, ele nega o problema da auto-reflexão. ${ }^{17} \mathrm{Q}$ uando M arx fala da relação entre a base e a superestrutura, ele se limita à produção material, o que seria um reducionismo de sua teoria. Parece, afinal, que $M$ arx rejeita uma discussão sobre a linguagem, pois na I deologia alemã, ${ }^{18}$ Marx e Engels afirmam que a consciência e a linguagem são os produtos sociais. Já, para H egel, a discussão sobre a linguagem ainda fazia sentido. Ele fala sobre a certeza sensual, na qual, dependendo da posição do observador, os objetos podem desaparecer, mas não o próprio geral. Este se guarda na linguagem, uma vez que ele é a verdade da certeza sensual. Feuerbach, por sua vez, não acredita que assim se negue a certeza sensual e que o geral seja mostrado como a verdade do real; por conseguinte, 0 pensamento articulado na linguagem é apenas o predicado do ser concreto. ${ }^{19} \mathrm{M}$ arx irá seguir essa intenção de Feuerbach, porém criticando a estática de sua posi ção que ficou ligada ao objeto sensual e não à atividade sensual, razão pela qual Feuerbach ainda não chegou até os pressupostos sociais da alienação. N o entanto, de onde 
saiu a possibilidade de pensar o capitalismo e reconstruir a teoria social usando o paradigma da linguagem? Por que seguir esse caminho da crítica contra Marx? Esta será uma das próximas perguntas que devemos fazer.

Poderíamos concluir que $\mathrm{H}$ egel questiona a metafísica da subjetividade kantiana, embora não questione a própria metafísica, pois nele temosainda o espírito em excesso; com isso, o reducionismo hegeliano se encontraria na perspectiva da falta de reflexão acerca das condições dessa metafísica. Por sua vez, M arx busca superar 0 idealismo alemão a partir da pergunta sobre as condiç̧̃es materiais da produção, mas, desse modo, encontramos nele ainda o material em demasia; seu reducionismo seria, então, a falta de reflexão sobre as condições dessa constituição. Portanto, o pensamento reflexivo seria a base para criticar tanto $\mathrm{H}$ egel quanto Marx. Mas, de onde saiu essa possibilidade? De onde vai sair a linguagem como a possibilidade para se pensar o novo paradigma da filosofia e do social? E ainda que seja o novo paradigma, já mencionamos a possibilidade de pensar sem paradigmas. Liberar-se da metafísica seria pensar sem paradigmas e, conseqüentemente, articular a possibilidade da emancipação, que seria também a emancipação dos paradigmas.

Dito isto, o que dizer hoje sobre Marx? Q uais são as suas dúvidas? Primeiramente, elas poderiam nascer dessa crença de que 0 processo objetivo vai conduzir à emancipação. 0 bjetivando-a, M arx ainda retém um certo positivismo da própria posição; além disso, a crença de que a classe operária é o sujeito da mudança do social também provoca dúvidas. Por fim, mesmo falando sobre as mudanças, sobre o comunismo como processo, resta um certo essencialismo no pensamento de Marx.

D efendo ainda que $M$ arx ainda é um pensador de grande relevância, pois, como o sistema não mudou, a questão sobre a emancipação ain da fica em aberto. A crítica do fetichismo continua sendo um grande motivo para o pensamento, tanto do jovem como do velho Marx, do Marx filósofo e do M arx economista. Ele pensa 
a economia como filósofo, como alguém que quer mudar o mundo, suprimindo, em sua obra, a diferença entre economia e filosofia. Poderíamos também dizer que a crítica do fetichismo seria capaz de repensar não só o capitalismo, mas toda a história; os filósofos poderiam refletir como a estática, ou uma certa metafísica da presença, determinou a história da filosofia. É mesmo provável que o fetichismo na filosofia comece já com Platão, o que faz de sua crítica uma grande sugestão para nós, para nossa vida cotidiana, para repensar a estática de nossa própria vida. Essa crítica do fetichismo seria uma abertura para o criativo; por conseguinte, pensar o fetichismo de nossa consciência e do social, em todos os níveis, ainda é um projeto marxista.

ABSTRACT : M arx often praises the greatness of $\mathrm{H}$ egelian for its affirmation of work. We could comprehend the task $M$ arx assigned himself as that of holding on to this H egelian idea, while liberating it from metaphysics. Work without the metaphysics - this could be, in few words, the inference that $\mathrm{M}$ arx wants to take from the philosophy of $\mathrm{H}$ egel.

Key words: Emancipation, ideology.

\section{Notes}

1. Feuerbach, L. A essência do cristianismo. Campinas, 1997. p. 57.

2. Falei sobre isso no livro Filosofia da comunicação. Brasília, 2002, partes I. 1 el. 3.

3. M ARx, K. Para a questão judaica. Lisboa, 1997. N essa obra se coloca a questão da emancipação de uma forma explícita.

4. MARX, K. M anuscritos econômico-filosóficos. São Paulo, 1985. p. 37.

5. Ibidem, p. 51.

6. MarX, K., Engels, F. A sagrada família. São Paulo, 1987. p. 7.

7. BöHLER, D. M etakritik der M arxschen Ideologiekritik. Frankfurt, 1971.

8. MARX, K. Frühschriften. Stuttgart, 1962. p. 604. 
9. A sugestão de Böhler é que a mediação entre o ideal e o real poderia ser pensada na idéia da linguagem. Assim, a crítica de Böhler contra Marx está de acordo com os argumentos de H abermas (BöHLeR, op. cit., p. 40).

10. BöHLER, op. cit., p. 45.

11. Castoriadis, C. L'institution imaginaire de la société. Paris, 1960.

12. Isso poderia ser também o contexto para uma análise da diferença entre os conceitos da ação em $\mathrm{H}$ annah A rendt e M arx.

13. U ma analogia com 1968 poderia ser feita. Respondendo às perguntas de Sartre, Daniel Cohn-Bendit, um dos líderes do movimento, fala: "A força do nosso movimento reside justamente na espontaneidade incontrolável em que se apóia [...]. Para isso é necessário evitar, de imediato, o surgimento de uma organização, a definição de um programa que seriam inevitavelmente paralisantes. A única chance do movimento é justamente esta desordem" (G o m Es, F. A . A rebelião dos jovens - Paris, 1968. Porto Alegre, 1968).

14. BöHLER, op. cit., p. 76.

15. I bidem, p. 93.

16. Ibidem, p. 54.

17. BöHLER, op. cit., p. 93.

18. M ArX, K.; Engels, F. A ideologia alemã. São Paulo, 1998. p. 24 e 25.

19. Feu erbach, L. Sämtliche W erke, II, Stuttgart, 1959. p. 239. 